\title{
Correction to: Phage Display, Peptide Production and Biological Assessment of Key Sequence of TGF- $\beta 1$
}

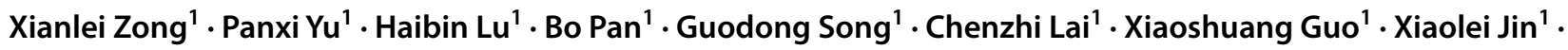 \\ Duyin Jiang ${ }^{2}$
}

Published online: 14 August 2020

(c) Springer Nature B.V. 2020

\section{Correction to: \\ International Journal of Peptide Research and \\ Therapeutics (2019) 25:1217-1223 \\ https://doi.org/10.1007/s10989-018-9774-x}

The original version of this article unfortunately contained an error in Results section.

The authors isolated 10 specific sequences similar to that of TGF- $\beta 1$, and chosen 7 key sequences to generate the bioactive peptides of TGF- $\beta 1$. Finally, they found only one model peptide can bind to and play biological effect on fibroblasts.
In article, it was inadvertently stated that No. 4 model peptide (presented in Table 3) could bind to and promote proliferation of fibroblasts, but actually No. 2 model peptide (presented in Table 3 ) is the only peptide with biological effects.

Publisher's Note Springer Nature remains neutral with regard to jurisdictional claims in published maps and institutional affiliations.

Xianlei Zong and Panxi Yu contributed equally to this work.

The original article can be found online at https://doi.org/10.1007/ s10989-018-9774-x.

Xiaolei Jin

professor.jin@yahoo.com

Duyin Jiang

jdybs2@vip.163.com

1 Plastic Surgery Hospital, Chinese Academy of Medical Sciences and Peking Union Medical College, 33 Badachu Road, Shijingshan District, Beijing 100144, China

2 Department of Burns and Plastic Surgery, The Second Hospital of Shandong University, 247 Beiyuan Road, Tianqiao District, Jinan 250033, Shandong, China 